$\underline{\text { Revised Supporting Information (ap-2021-00846e.R1) }}$

\title{
Dithia-Crown-Ether Integrated Self-Exfoliated Polymeric Covalent Organic Nanosheets for Selective Sensing and Removal of Mercury
}

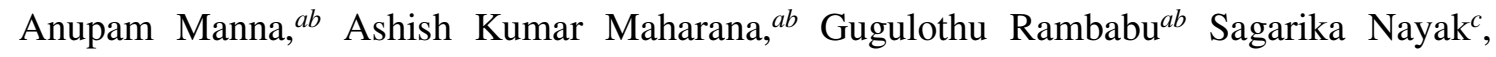
Suddhasatwa Basu, ${ }^{a}$ and Sanjib Das ${ }^{*} a b$

${ }^{a}$ Materials Chemistry Department, CSIR-Institute of Minerals \& Materials Technology, Bhubaneswar 751013, India.

${ }^{b}$ Academy of Scientific and Innovative Research (AcSIR), Ghaziabad 201002, India.

${ }^{c}$ School of Physical Sciences, National Institute of Science Education and Research (NISER), Jatni, 752050, India.

\section{*Corresponding Author: sanjibdas@immt.res.in}

\section{Experimental Section:}

\section{Materials}

All reagents were purchased from commercially available sources and utilized as received unless otherwise mentioned. Phlorogucinol, Trifluoroacetic acid, Hexamethylene-tetraamine, Potassium acetate, 2,3-Dihydrxynaphthalene, Potassium carbonate, 1,1' Bis(diphenylphosphino)ferrocene, Dicholoro[1,1'bis(diphenylphosphino)ferrocene]palladium (II), Tetrakis(triphenylphosphine)palladium(0), Mesitylene were purchased from Alfa Aesar. Bis(2-mercaptoethyl) was procured from TCI Chemicals. Ethanol, n-Butanol, 4Bromoanilline, Bis-(pinacolato)diboron, Thionyl chloride, Bromine, Lithium carbonate were purchased from Spectrochem Pvt. Ltd. India. Al solvents were purchased from Spectrochem Pvt. Ltd. India and distilled and dried as per their requirement. Column chromatography was performed with silica gel (60-120 mesh, Spectrochem Pvt. Ltd. India). The metal ions solution such as $\mathrm{Hg}$ (II), $\mathrm{Pb}$ (II), $\mathrm{Cd}$ (II), $\mathrm{Ag}$ (I), $\mathrm{Zn}$ (II), $\mathrm{Cu}$ (II), $\mathrm{Cr}$ (III), $\mathrm{Ca}$ (II), $\mathrm{Mg}$ (II), $\mathrm{Mn}$ (II), $\mathrm{Fe}(\mathrm{III}), \mathrm{Na}(\mathrm{I}), \mathrm{K}(\mathrm{I})$ of $1000 \mathrm{ppm}$ strength $(1 \mathrm{~g} / \mathrm{L})$ was received as a standard solution from Merck and diluted as per the experimental requirement.

\section{Measurements}

Solution ${ }^{1} \mathrm{H}$ and ${ }^{13} \mathrm{C}$ NMR spectra were recorded on BRUKER ${ }^{\circledR}$ ULTRASHIELD 400 NMR spectrometer at room temperature in $\mathrm{CDCl}_{3} / \mathrm{DMSO}-\mathrm{d}_{6}$ solvent utilizing tetramethylsilane (TMS) as an internal standard. The ${ }^{13} \mathrm{C}$ cross polarization magic angle spinning (CP-MAS) NMR was performed on JEOL JNM-ECX400II solid-state NMR spectrometer. FT-IR spectra were measured using a Perkin Elmer Spectrum-GX spectrophotometer in KBr pallet medium. 
FE-SEM images were captured using Carl Zeiss AG Supra Gemini 55 equipped with OXFORD energy dispersive X-ray spectrometer operating at an accelerating voltage of 15 $\mathrm{kV}$. Samples suspended in methanol are drop casted on cleaned silicon substrate followed by gold coating. Powder X-ray diffraction data for the samples were collected in the reflection mode at room temperature on a PANanalytical XPERT PRO using monochromated $\mathrm{Cu}-\mathrm{K} \square$ $(\lambda=1.54060 \AA)$ radiation with a scan rate of $2^{\circ} \mathrm{min}^{-1}$ and a step size of $2 \theta=0.01^{\circ}$. The X-ray tube operated at a voltage of $30 \mathrm{kV}$ and a current of $30 \mathrm{~mA}$. Thermogravimetric analysis (TGA) was carried out under nitrogen atmosphere using Netzsch STA 449F3-jupiter instrument with a heating rate of $10{ }^{\circ} \mathrm{C} / \mathrm{min}$. Gas adsorption-desorption was measured by using a fully automated Quantachrome Autosorb-iQ surface area \& pore size analyser. Before gas adsorption-desorption measurement, the sample was outgassed at $140{ }^{\circ} \mathrm{C}$ for 12 hours. Surface area and pore size distribution was analysed utilizing $\mathrm{CO}_{2}$ isotherm measured at 195 K using dry ice-acetone bath. The pore size distribution was calculated using the HorváthKawazoe method. XPS analysis were recorded by PHI 5000 Versa Prob II, FEI Inc. with AES module comprising argon ion as well as C60 sputter guns. Elemental analysis (CHNS) experiment was carried out on Thermo Scientific Flash 2000 Organic Elemental Analyser with Thermal Conductivity Detector using column PQS SS $2 \mathrm{M} 6 \mathrm{X} 5 \mathrm{~mm}$ in oven at $75^{\circ} \mathrm{C}$ and Eager Experience Software. UV-Vis spectra were recorded on JASCO V-670 Spectrophotometer. Fluorescence titrations were carried out by FLS980, EDINBURGH PHOTONICS spectrofluorometer at $\lambda_{\mathrm{ex}}=480 \mathrm{~nm}$ with excitation and emission band width of $2 \mathrm{~nm}$. The metal ions concentrations were determined by using an Agilent 7900 ICP-MS instrument.

\subsubsection{Synthesis Procedure:}

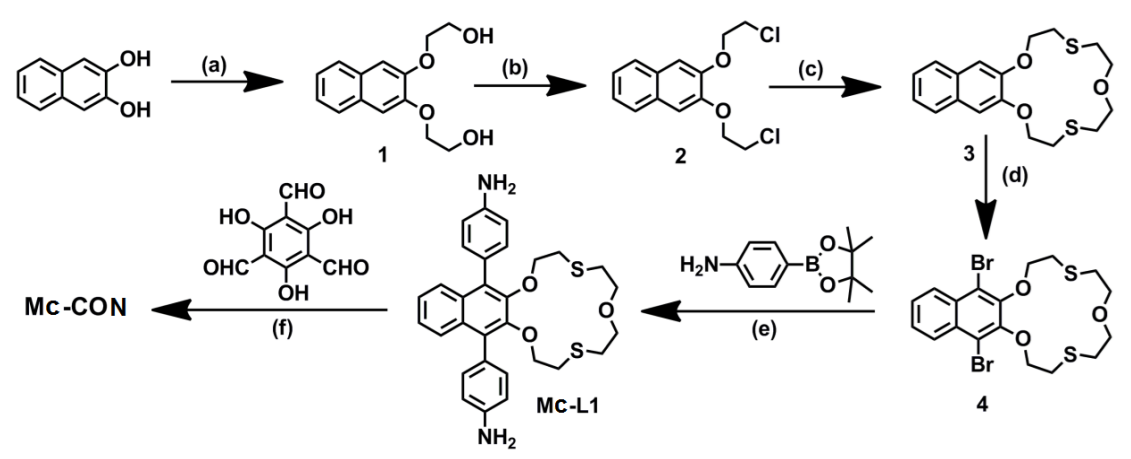

Reagents and conditions: (a) 2-Chloroethanol, $\mathrm{NaOH}, \mathrm{n}-\mathrm{BuOH} / \mathrm{H}_{2} \mathrm{O}$, reflux, overnight; (b) Pyridine, $\mathrm{SOCl}_{2}$, Benzene, Reflux, $5 \mathrm{~h}$; (c) Bis(2-mercaptoethyl) ether, $\mathrm{Li}_{2} \mathrm{CO}_{3}, \mathrm{EtOH} / \mathrm{H}_{2} \mathrm{O}$ (1:1), Reflux, $36 \mathrm{~h}$; (d) $\mathrm{Br}_{2}, \mathrm{AcOH}$, room temperature, overnight; (e) $\mathrm{Pd}\left(\mathrm{PPh}_{3}\right)_{4}, \mathrm{~K}_{2} \mathrm{CO}_{3}, 1$,4-dioxane/water $(5: 1), 100{ }^{\circ} \mathrm{C}$, $\mathrm{N}_{2}$ atmosphere, $36 \mathrm{~h}$; (f) 1,4-Dioxane/Mesitylene (1:1), Acetic acid (6M), $120^{\circ} \mathrm{C}, 3 \mathrm{~d}$. 
Scheme S1. Synthetic route to prepare macrocycle functionalized aromatic diamino building block (Mc-L1).

Compound 1: ${ }^{\text {S1 }}$ To a boiling solution of 2,3-dihydroxynapthalene (2 $\left.\mathrm{g}, 12.49 \mathrm{mmol}\right)$ and $\mathrm{NaOH}(1.49 \mathrm{~g}, 37.47 \mathrm{mmol})$ in degassed $\mathrm{n}-\mathrm{BuOH}(10 \mathrm{~mL})$ and water $(2 \mathrm{~mL})$, a solution of 2chloroethanol (3.52 g, $43.715 \mathrm{mmol})$ in degassed n-BuOH (20 mL) was added drop-wise over a period of $1 \mathrm{~h}$ under argon atmosphere. After addition is completed, the reaction mixture was refluxed for 4 days. The reaction mixture was cooled down to room temperature followed by evaporation of solvent under reduced pressure. The resulted residue was purified by column chromatography (silica gel and ethyl acetate; $R_{\mathrm{f}}-0.4$ ) resulting a white solid as compound $\mathbf{1}$. Yield: 2.3g (29.87 \%). ${ }^{1} \mathrm{H}$ NMR (400 MHz, $\left.\mathrm{CDCl}_{3}\right): \delta(\mathrm{ppm})=7.49-7.47(\mathrm{~m}, 2 \mathrm{H}), 7.15-7.13$ (m, 2H), $4.01(\mathrm{t}, \mathrm{J}=4.0,4 \mathrm{H}), 3.81(\mathrm{t}, \mathrm{J}=8.0,4 \mathrm{H})$.

Compound 2: ${ }^{\mathrm{S} 1}$ To a boiling solution of compound 2 (2 g, $\left.8.06 \mathrm{mmol}\right)$ and anhydrous pyridine $\quad(1.94 \mathrm{~mL}, 24.18 \mathrm{mmol})$ in anhydrous benzene $(15 \mathrm{~mL}), \mathrm{SOCl}_{2}$ solution in anhydrous benzene $(10 \mathrm{~mL})$ was added drop-wise over a period of $1 \mathrm{~h}$. After complete addition, the mixture was refluxed for $5 \mathrm{~h}$ in an oil bath. The reaction mixture was cooled down to room temperature followed by drop-wise addition of $15 \% \mathrm{HCl}(10 \mathrm{~mL})$. The reaction mixture was extracted with $\mathrm{CHCl}_{3}(3 \times 50 \mathrm{~mL})$, dried over anhydrous $\mathrm{MgSO}_{4}$, and evaporated in a rotary evaporator under reduced pressure. The solid residue was purified by column chromatography (silica gel, $\mathrm{CHCl}_{3} ; R_{\mathrm{f}}-0.7$ ) resulting Compound 2 as white solid. Yield: 1.7g (74 \%). ${ }^{1} \mathrm{H}$ NMR (400 MHz, $\left.\mathrm{CDCl}_{3}\right): \delta(\mathrm{ppm})=7.68-7.65(\mathrm{~m}, 2 \mathrm{H}), 7.36-7.34(\mathrm{~m}$, $2 \mathrm{H}), 7.18(\mathrm{~s}, 2 \mathrm{H}), 4.35(\mathrm{t}, \mathrm{J}=6.0,4 \mathrm{H}), 3.89(\mathrm{t}, \mathrm{J}=6.0,4 \mathrm{H}) .{ }^{13} \mathrm{C} \mathrm{NMR}\left(100 \mathrm{MHz}, \mathrm{CDCl}_{3}\right): \delta$ $(\mathrm{ppm})=148.43,129.61,126.49,124.78,69.32,41.75$.

Compound 3: ${ }^{\mathrm{S} 1}$ A solution of Compound 2 (0.5 g, $\left.1.75 \mathrm{mmol}\right)$ and bis(2-mercaptoethyl) ether $(0.29 \mathrm{~g}, 2.1 \mathrm{mmol})$ in ethanol $(90 \mathrm{~mL})$ was added drop-wise over a period of $1 \mathrm{~h}$ to a reflux solution of $\mathrm{Li}_{2} \mathrm{CO}_{3}(0.646 \mathrm{~g}, 8.75 \mathrm{mmol})$ in 1:1 ethanol/water $(100 \mathrm{~mL})$ mixture under $\mathrm{N}_{2}$ atmosphere. The reaction mixture was refluxed for $36 \mathrm{~h}$ and then cooled down to room temperature. The solvent was evaporated to dryness followed by addition of water and extracted the mixture by $\mathrm{CHCl}_{3}(3$ x $50 \mathrm{~mL})$. Organic layer was dried over anhydrous $\mathrm{MgSO}_{4}$ followed by evaporation in a rotary evaporator under reduced pressure. The residue was purified by column chromatography (silica gel and $\mathrm{CHCl}_{3}, R_{\mathrm{f}}-0.7$ ) obtaining white solid as Compound 3. Yield: $0.5 \mathrm{~g}(81.36 \%) .{ }^{1} \mathrm{H}$ NMR (400 MHz, $\left.\mathrm{CDCl}_{3}\right): \delta(\mathrm{ppm})=7.66-7.64(\mathrm{~m}$, 
2H), 7.34-7.31 (m, 2H), $7.09(\mathrm{~s}, 2 \mathrm{H}), 4.35(\mathrm{t}, \mathrm{J}=5.2,4 \mathrm{H}), 3.83(\mathrm{t}, \mathrm{J}=6.8,4 \mathrm{H}), 3.13(\mathrm{t}, \mathrm{J}=$ 5.0, 4H), $2.99(\mathrm{t}, \mathrm{J}=6.8,4 \mathrm{H}) .{ }^{13} \mathrm{C} \mathrm{NMR}\left(100 \mathrm{MHz}, \mathrm{CDCl}_{3}\right): \delta(\mathrm{ppm})=148.89,129.29$, $126.34,124.32,107.85,71.72,70.87,31.48,31.25$.

Compound 4: ${ }^{\mathrm{S} 2}$ To a stirred solution of Compound $3(0.3 \mathrm{~g}, 0.86 \mathrm{mmol})$ in acetic acid (5 $\mathrm{mL})$, a solution of $\mathrm{Br}_{2}(0.31 \mathrm{~g}, 1.94 \mathrm{mmol})$ in acetic acid $(2 \mathrm{~mL})$ was added drop-wise at room temperature. The mixture was stirred for overnight at room temperature resulting a white suspension. The white solid was filtered, washed with water and then dried in air. The as-prepared product is recrystallized from methanol producing an analytically pure product as Compound 4. Yield: $0.336 \mathrm{~g}(77.4 \%)$. ${ }^{1} \mathrm{H}$ NMR (400 MHz, $\left.\mathrm{CDCl}_{3}\right): \delta(\mathrm{ppm})=8.23-8.21(\mathrm{~m}$, 2H), 7.57-7.54 (m, 2H), $4.34(\mathrm{t}, \mathrm{J}=7.2,4 \mathrm{H}), 3.80(\mathrm{t}, \mathrm{J}=5.0,4 \mathrm{H}), 3.27(\mathrm{t}, \mathrm{J}=7.4,4 \mathrm{H}), 2.89$ $(\mathrm{t}, \mathrm{J}=5.0,4 \mathrm{H}) .{ }^{13} \mathrm{C} \mathrm{NMR}\left(100 \mathrm{MHz}, \mathrm{CDCl}_{3}\right): \delta(\mathrm{ppm})=149.33,130.26,127.40,127.32$, $116.53,73.48,31.87,31.61$.

4-(4,4,5,5-tetramethyl-1,3,2-dioxaborolan-2-yl)aniline: ${ }^{52}$ The 4-(4,4,5,5-tetramethyl-1,3,2dioxaborolan-2-yl)aniline was synthesized according to the literature procedure. In a typical procedure, a mixture of 4-bromoanilline ( $3 \mathrm{~g}, 17.44 \mathrm{mmol})$, bis-(pinacolato)diboron (5.31 g, $20.93 \mathrm{mmol})$, and KOAc $(5.13 \mathrm{~g}, 52.32 \mathrm{mmol})$ were taken in a round bottom flask and purged the mixture with Argon for 5 mins. After purging, catalyst $\mathrm{Pd}(\mathrm{dppf})_{2} \mathrm{Cl}_{2}(0.412 \mathrm{~g}$, $0.505 \mathrm{mmol})$ and ligand 1,1'- Bis(diphenylphosphino)ferrocene $(0.289 \mathrm{~g}, 0.523 \mathrm{mmol})$ were added into the mixture followed by addition of anhydrous $100 \mathrm{~mL}$ of 1,4-dioxane. The resultant solution was purged for another 5 min with argon and heated at $100{ }^{\circ} \mathrm{C}$ for 2 days under stirring. The reaction mixture was cooled to room temperature followed by addition of water and extracted with DCM $(4 \times 50 \mathrm{~mL})$. The organic layer was drier over anhydrous $\mathrm{MgSO}_{4}$ and evaporated in a rotary evaporator under reduced pressure to get a brown solid. The as-prepared solid was purified by column chromatography (Silica, DCM, $R_{\mathrm{f}}-0.3$ ) to obtain the desired compound as white solid. Yield: $1.9 \mathrm{~g},(49.5 \%) .{ }^{1} \mathrm{H}$ NMR (400 MHz, $\left.\mathrm{CDCl}_{3}\right): \delta(\mathrm{ppm})=7.63-7.61(\mathrm{~d}, 2 \mathrm{H}), 6.67-6.64(\mathrm{~d}, 2 \mathrm{H}), 3.81(\mathrm{~s}, 2 \mathrm{H}), 1.32(\mathrm{~s}, 12 \mathrm{H})$.

1,3,5-triformylphloroglucinol: ${ }^{26}$ This compound was synthesized according to the reported procedure with slight medication. In a typical modified procedure, hexamethylenetetramine $(7.4 \mathrm{~g}, 52.79 \mathrm{mmol})$ was added into a solution of phloroglucinol $(2.8 \mathrm{~g}, 22.2 \mathrm{mmol})$ in trifluoroacetic acid $(45 \mathrm{ml})$ under argon atmosphere and heated the reaction mixture at $100{ }^{\circ} \mathrm{C}$ under stirring for $2.5 \mathrm{~h}$ followed by very slow addition of $3 \mathrm{M} \mathrm{HCl}(150 \mathrm{ml})$ into the reaction mixture while keeping the temperature at $100{ }^{\circ} \mathrm{C}$. The mixture was continuing heating for another $1 \mathrm{~h}$. After cooled to room temperature, the solution was filtered over celite bed. The 
filtrate was extracted with DCM (6 x $50 \mathrm{~mL})$ and dried over anhydrous $\mathrm{MgSO}_{4}$. The solvent was removed under vacuum using rotary evaporator to get a solid which was washed by hot ethanol $(20 \mathrm{ml})$ resulting a dull orange coloured solid as the desired compound. Yield: 0.825 g (16.28 \%). ${ }^{1} \mathrm{H}$ NMR (400 MHz, $\left.\mathrm{CDCl}_{3}\right): \delta(\mathrm{ppm})=14.12(\mathrm{~s}, 3 \mathrm{H}), 10.15(\mathrm{~s}, 3 \mathrm{H}) ;{ }^{13} \mathrm{C} \mathrm{NMR}$ $\left(100 \mathrm{MHz}, \mathrm{CDCl}_{3}\right): \delta(\mathrm{ppm})=190.99,172.36,101.65$.

Mc-L1: ${ }^{26}$ In a two-neck round bottom flask, a mixture of Compound 4 (1 g, $\left.1.97 \mathrm{mmol}\right)$, 4(4,4,5,5-tetramethyl-1,3,2-dioxaborolan-2-yl)aniline (1.29 g, $5.9 \mathrm{mmol}), \mathrm{Pd}\left(\mathrm{PPh}_{3}\right)_{4}(0.303 \mathrm{~g}$, $0.262 \mathrm{mmol})$, and $\mathrm{K}_{2} \mathrm{CO}_{3}(0.815 \mathrm{~g}, 5.9 \mathrm{mmol})$ in 1,4-dioxane $(40 \mathrm{~mL})$ and water $(8 \mathrm{~mL})$ was heated with stirring at $100{ }^{\circ} \mathrm{C}$ under argon atmosphere for $36 \mathrm{~h}$. After cooling down to room temperature, water was added to the reaction mixture and the resulted suspension was extracted with DCM (4 x $50 \mathrm{~mL})$. The organic layer was further washed with fresh water followed by drying over anhydrous $\mathrm{Na}_{2} \mathrm{SO}_{4}$ and evaporated to dryness under reduced pressure using rotary evaporator. The resulted thick brown liquid was purified by column chromatography (silica gel and ethyl acetate/petroleum ether $\left.(1: 1) ; R_{\mathrm{f}}-0.5\right)$ to obtain an off white solid as Compound Mc-L1. Yield: 0.780g (74 \%). ${ }^{1} \mathrm{H}$ NMR (400 $\left.\mathrm{MHz}, \mathrm{CDCl}_{3}\right)$ : $\delta$ $(\mathrm{ppm})=7.64-7.62(\mathrm{~m}, 2 \mathrm{H}), 7.28-7.25(\mathrm{~m}, 2 \mathrm{H}), 7.21(\mathrm{~d}, \mathrm{~J}=8.4,4 \mathrm{H}) 6.82(\mathrm{~d}, \mathrm{~J}=8.4,4 \mathrm{H})$, $4.0441(\mathrm{t}, \mathrm{J}=7.4,4 \mathrm{H}), 3.71(\mathrm{t}, \mathrm{J}=5.2,4 \mathrm{H}), 2.83(\mathrm{t}, \mathrm{J}=7.4,4 \mathrm{H}), 2.75(\mathrm{t}, \mathrm{J}=5.2,4 \mathrm{H}) .{ }^{13} \mathrm{C}$ NMR (100 MHz, $\left.\mathrm{CDCl}_{3}\right): \delta(\mathrm{ppm})=148.55,145.51,132.05,131.67,131.02,126.16,125.99$, $124.75,114.86,73.05,72.98,31.47$.

Mc-CON: ${ }^{25}$ To a glass ampoule, 1,3,5-triformylphloroglucinol (25 mg, $\left.0.1189 \mathrm{mmol}\right)$ was added to a solution of Compound Mc-L1 (89 mg, $0.1784 \mathrm{mmol}$ ) in 1,4-dioxane/mesitylene (1:1) mixture $(6 \mathrm{~mL})$. The mixture is briefly sonicated for couple of minutes followed by addition of $300 \mu \mathrm{L}$ of acetic acid (6M) into the mixture. The ampoule was flash frozen in a liquid $\mathrm{N}_{2}$ bath, evacuated and purged with argon. The ampoule was flame sealed upon cooling up to room temperature and placed inside an isothermal oven at $120{ }^{\circ} \mathrm{C}$ for 3 days. The brownish yellow solid was isolated by centrifugation and washed with 1,4-dioxane $(2 \times 5$ $\mathrm{mL})$, THF $(3 \times 5 \mathrm{~mL})$, and finally with acetone $(3 \times 5 \mathrm{~mL})$. The as-synthesized product is further purified in a Soxhlet extractor with methanol $(12 \mathrm{~h})$ and then with acetone $(12 \mathrm{~h})$ followed by drying under vacuum at $80{ }^{\circ} \mathrm{C}$ for $24 \mathrm{~h}$ to obtained a dark yellow solid as McCON. Yield: $80 \mathrm{mg} .{ }^{13} \mathrm{C}$ CP-MAS NMR (100 MHz): $\delta(\mathrm{ppm})=186,150,140,133,127,121$, 116, 109, 75, 33. FT-IR: 1597, 1515, 1455, 1345, 1290, 1253, 1114, 999, 835, $767 \mathrm{~cm}^{-1}$. 


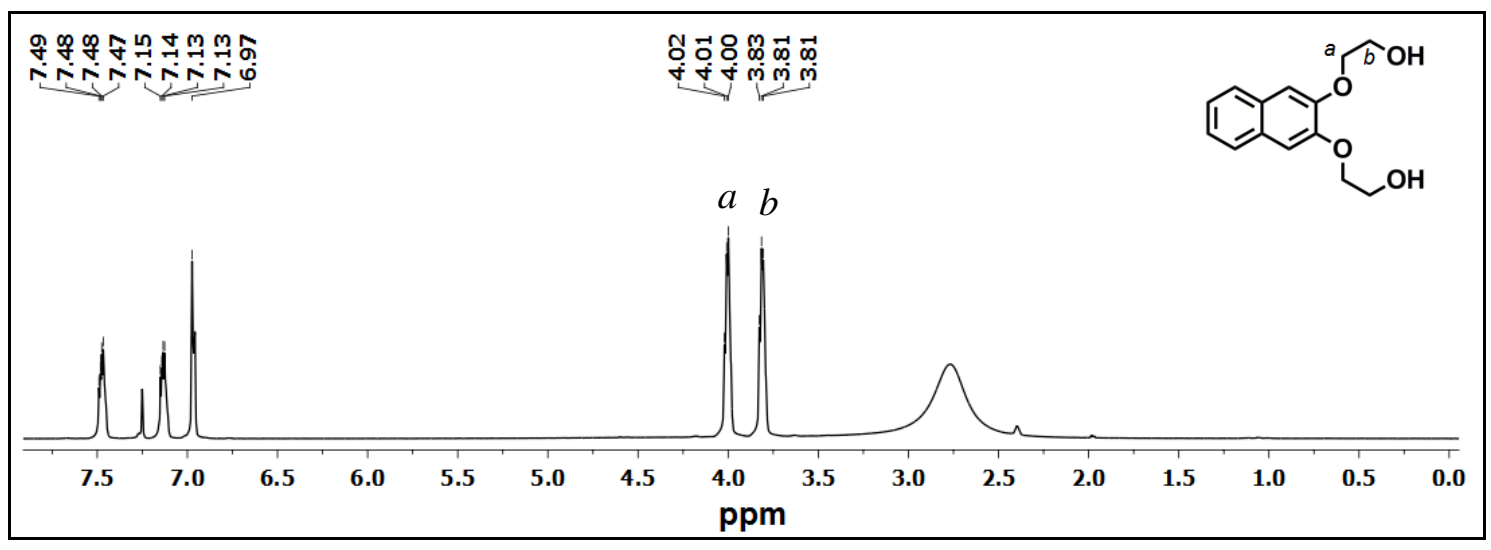

Figure S1. ${ }^{1} \mathrm{H}-\mathrm{NMR}$ of Compound 1.

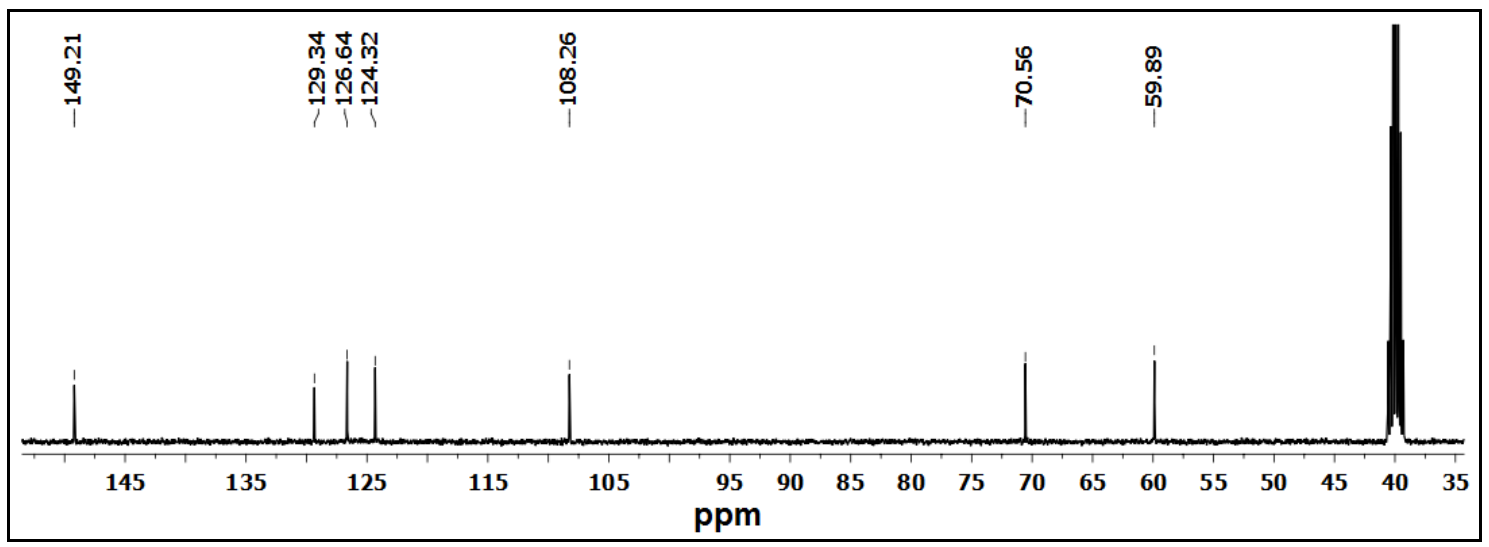

Figure S2. ${ }^{13} \mathrm{C}-\mathrm{NMR}$ of Compound 1.

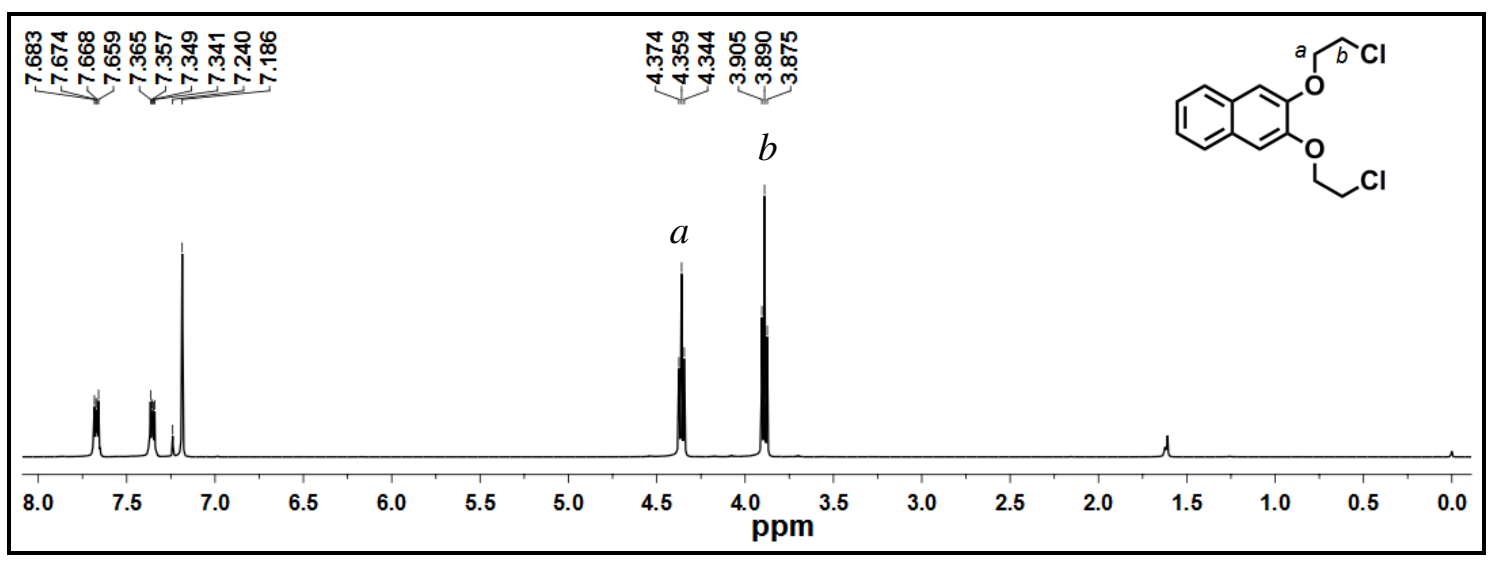

Figure S3. ${ }^{1} \mathrm{H}-\mathrm{NMR}$ of Compound 2. 


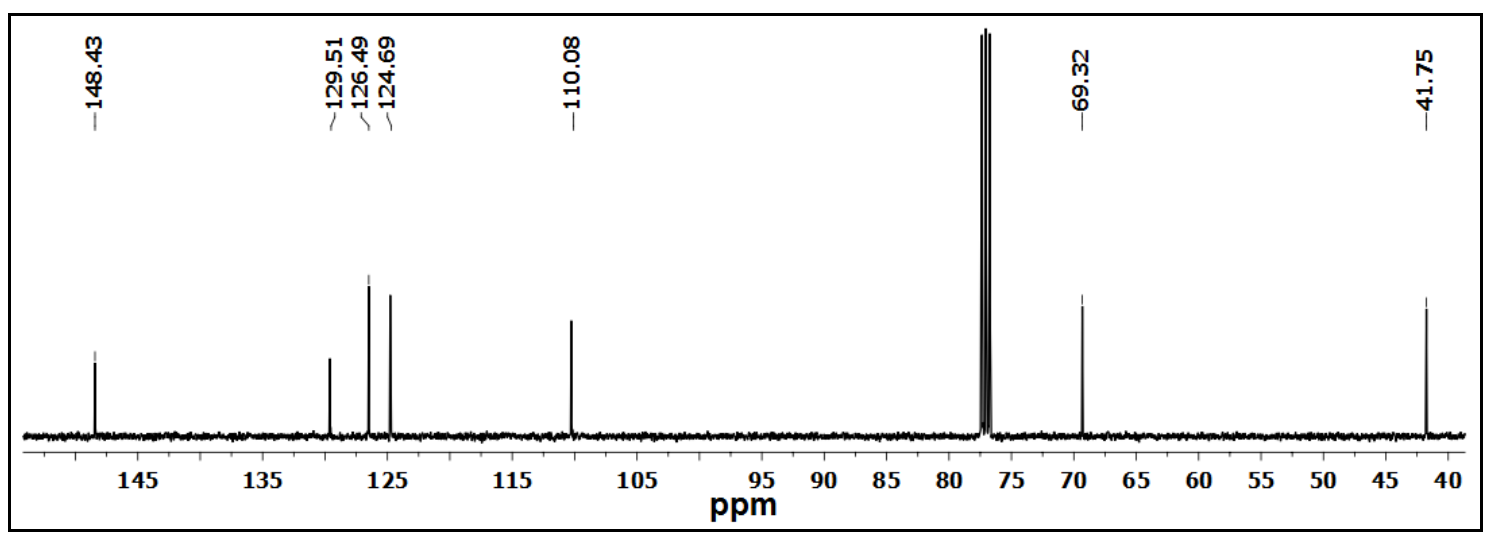

Figure S4. ${ }^{13} \mathrm{C}-\mathrm{NMR}$ of Compound 2.

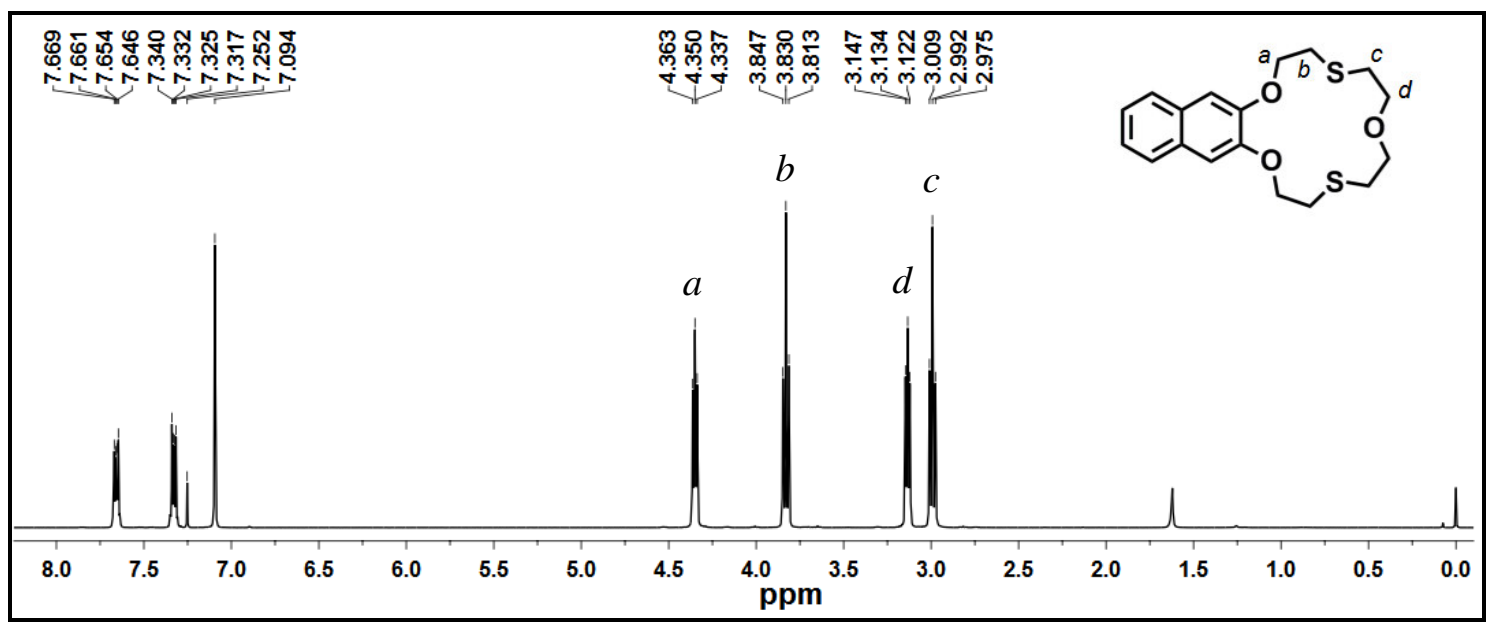

Figure S5. ${ }^{1} \mathrm{H}-\mathrm{NMR}$ of Compound 3.

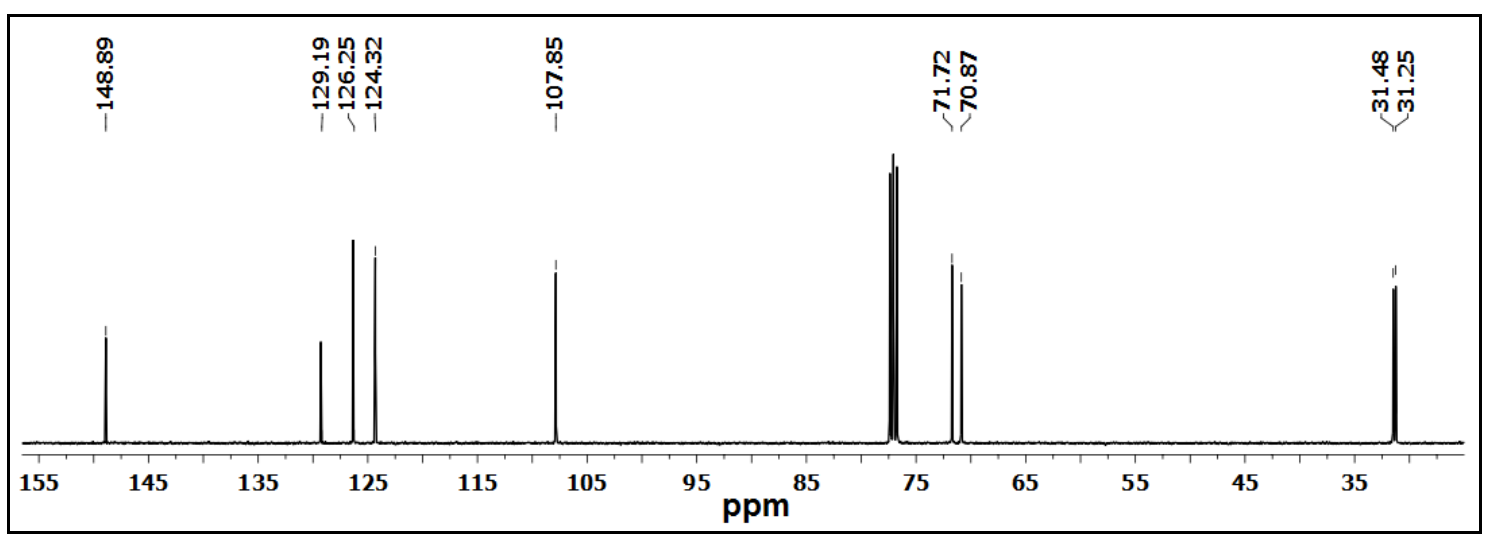

Figure S6. ${ }^{13} \mathrm{C}-\mathrm{NMR}$ of Compound 3. 


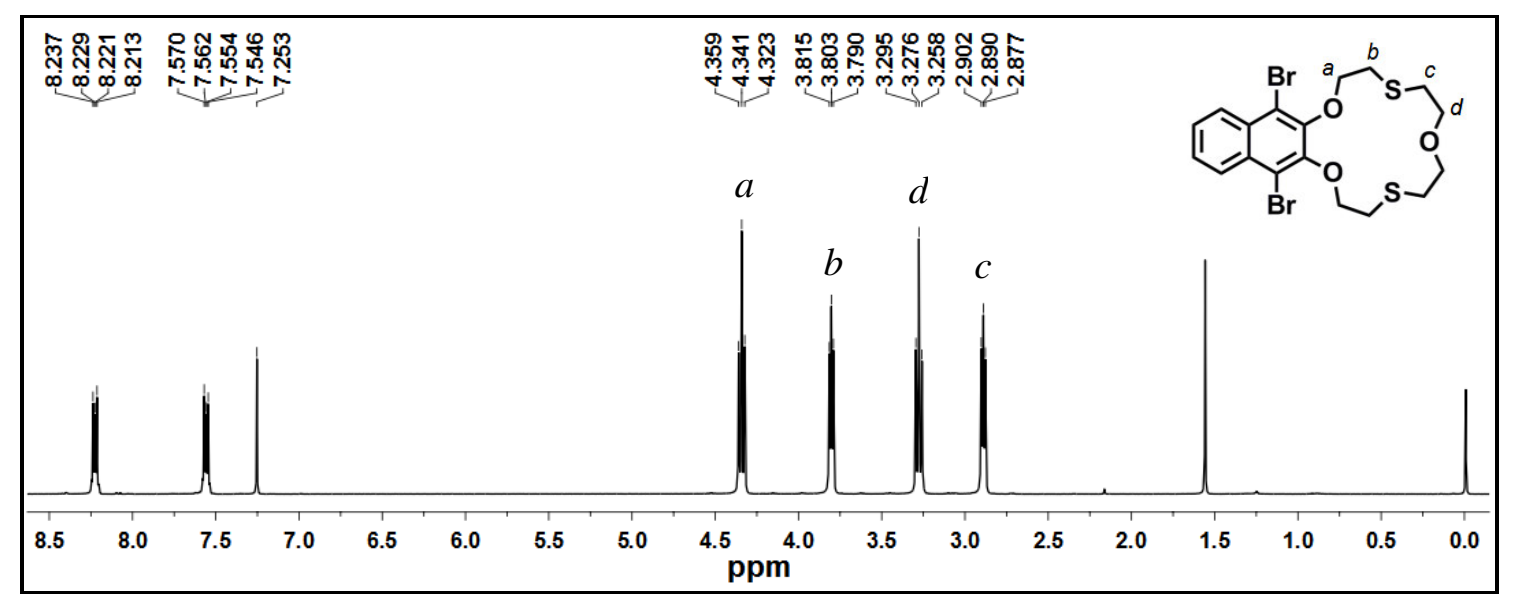

Figure S7. ${ }^{1} \mathrm{H}-\mathrm{NMR}$ of Compound 4.

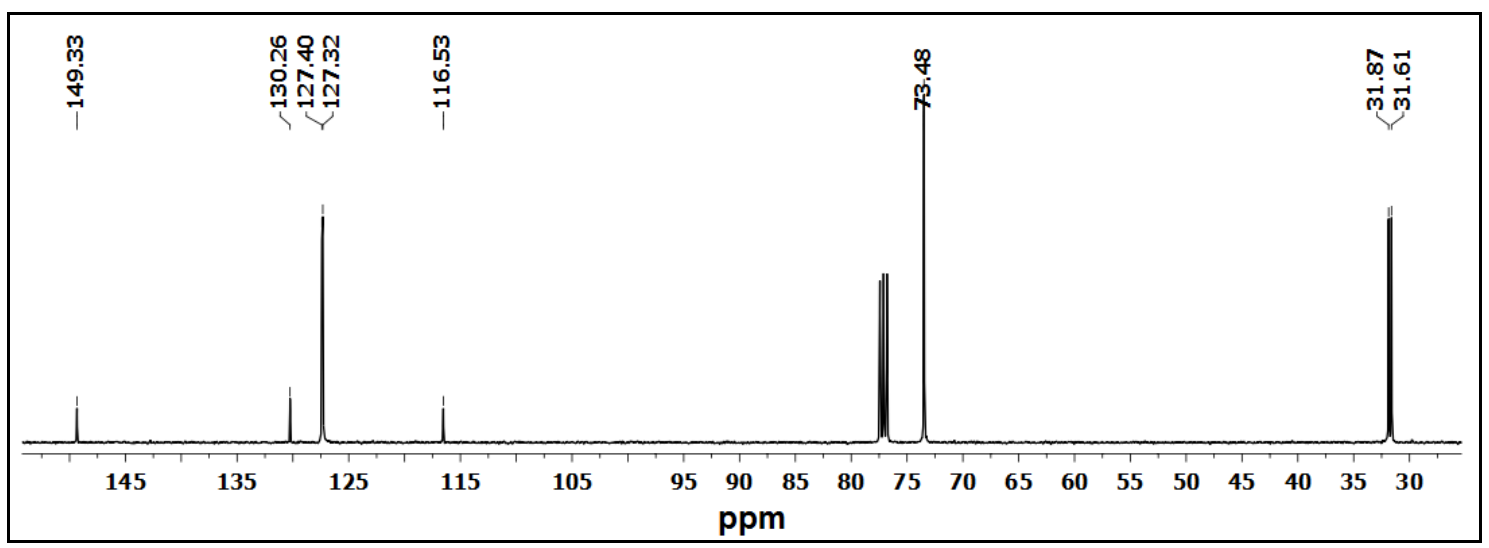

Figure S8. ${ }^{13} \mathrm{C}-\mathrm{NMR}$ of Compound 4.

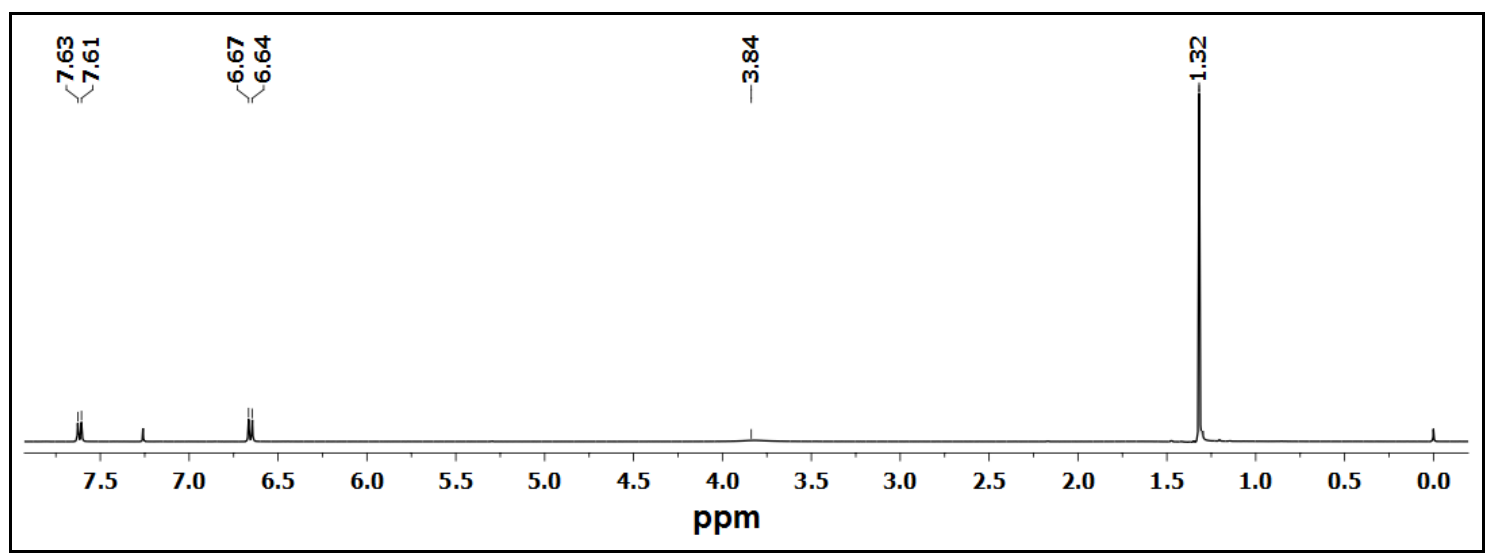

Figure S9. ${ }^{1} \mathrm{H}-\mathrm{NMR}$ of 4-(4,4,5,5-tetramethyl-1,3,2-dioxaborolan-2-yl)aniline. 


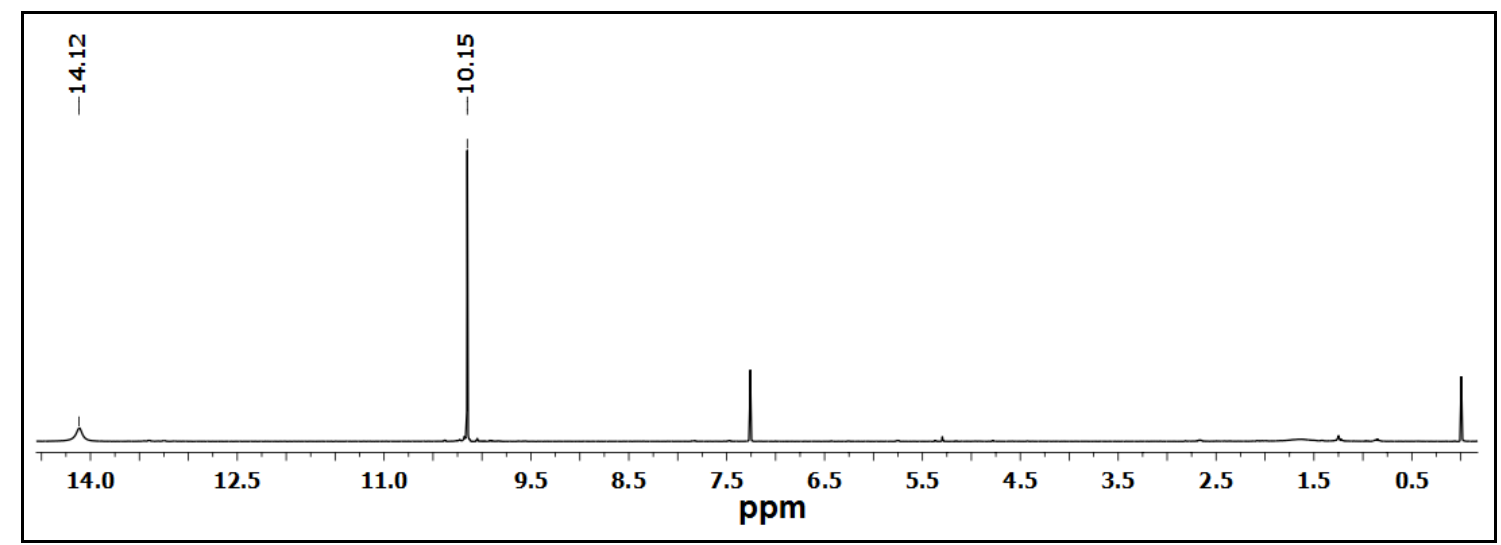

Figure S10. ${ }^{1} \mathrm{H}-\mathrm{NMR}$ of 1,3,5-triformylphloroglucinol.

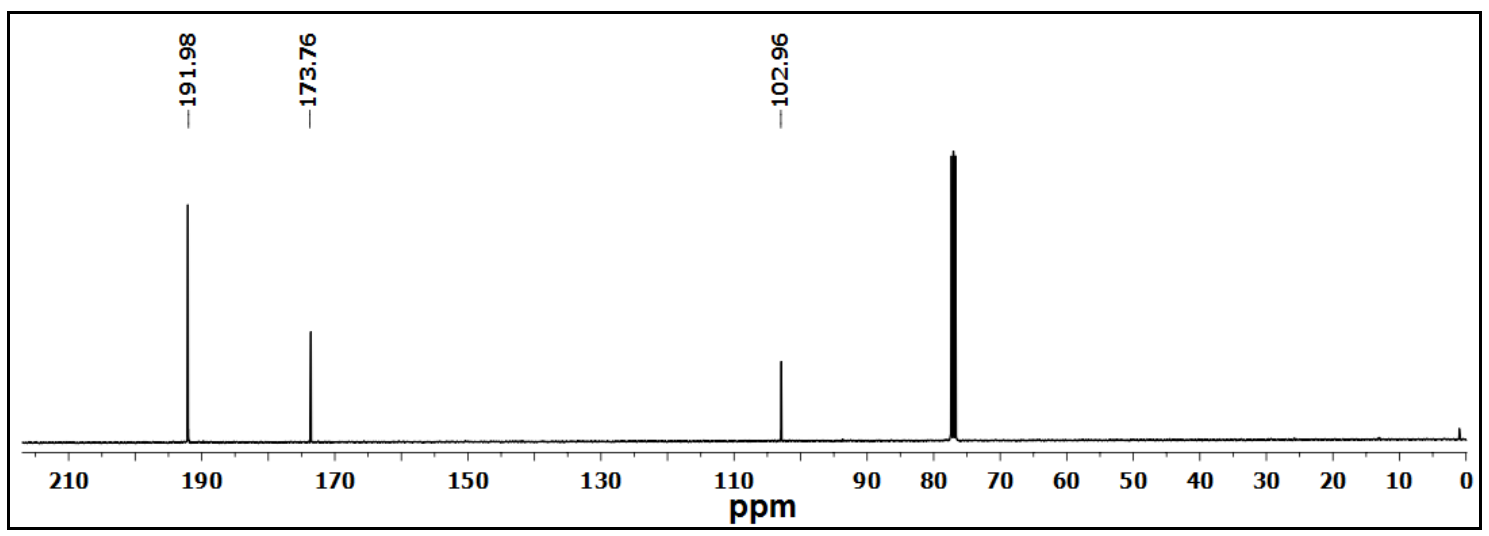

Figure S11. ${ }^{13} \mathrm{C}$-NMR of 1,3,5-triformylphloroglucinol.

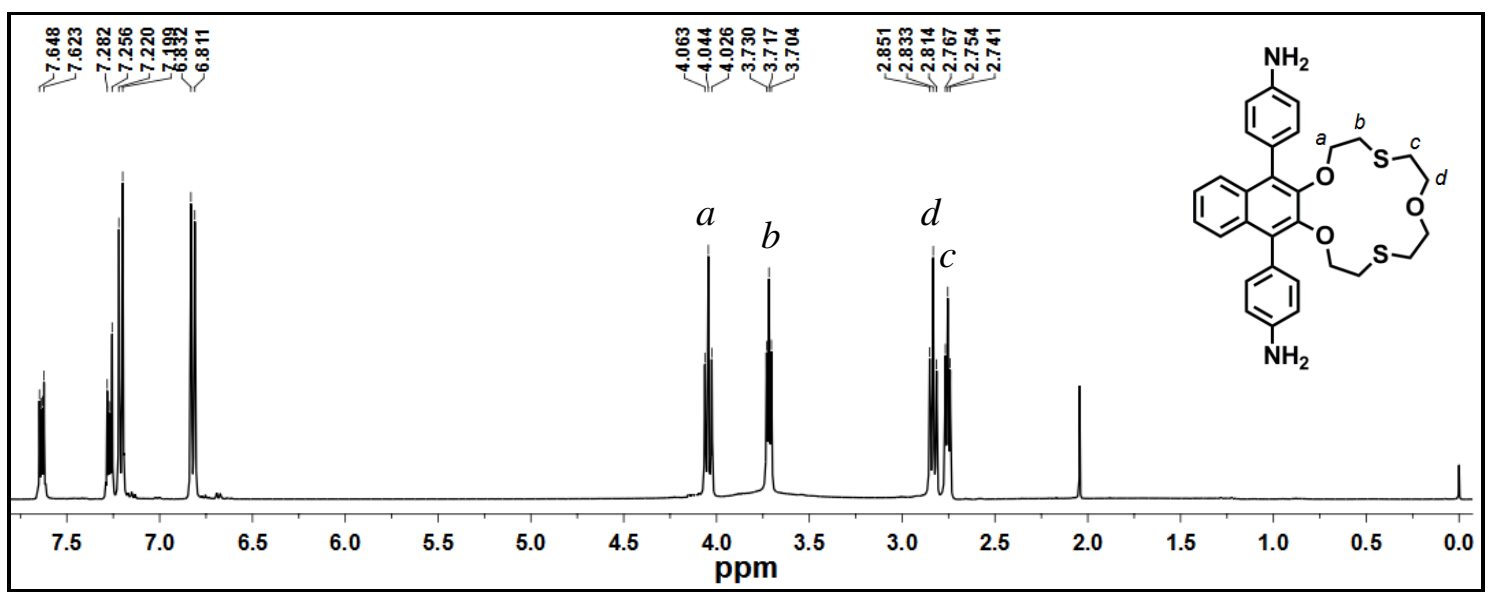

Figure S12. ${ }^{1} \mathrm{H}-\mathrm{NMR}$ of Mc-L1. 


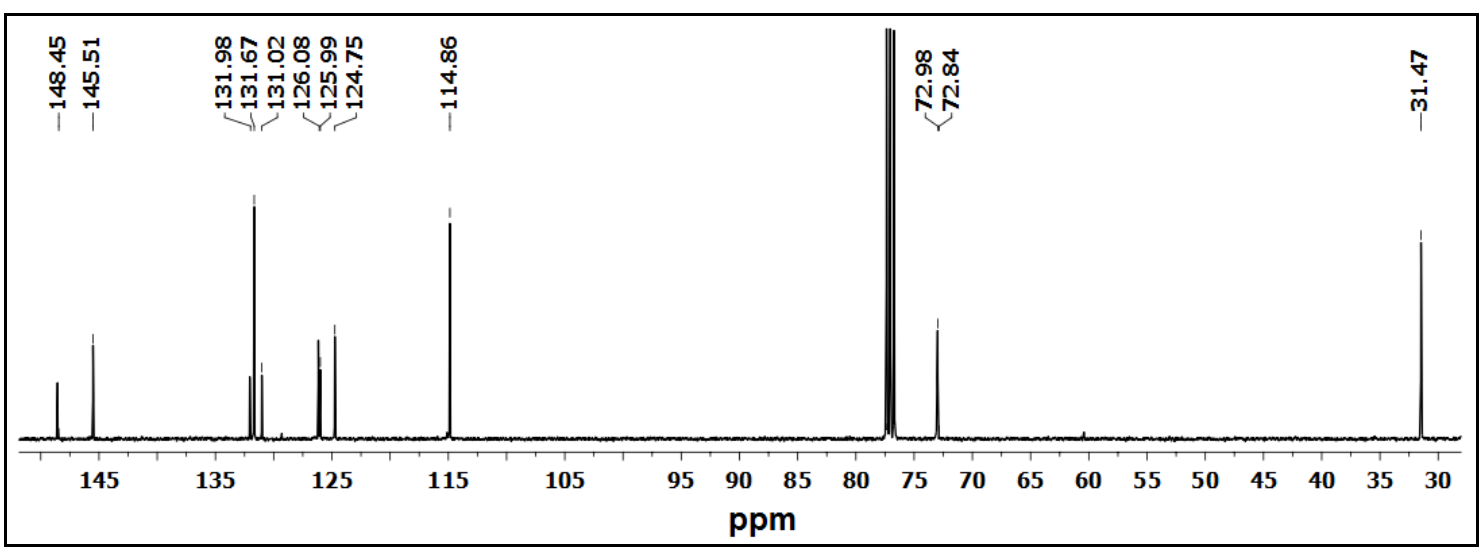

Figure S13. ${ }^{13} \mathrm{C}-\mathrm{NMR}$ of Mc-L1.

\section{General Experimental Procedures}

\section{Preparation of Fluorescence Probe for $\mathrm{Hg}^{2+}$ Titration:}

A stock suspension was prepared by sonicating $1 \mathrm{mg}$ of Mc-CON in $20 \mathrm{~mL}$ of water for 30 min. After then, $3 \mathrm{~mL}$ of stock dispersed solution was taken in a quartz cell of $1 \mathrm{~cm}$ path length. The fluorescence quenching titrations were carried out by incremental addition of 1 $\mathrm{mM}$ aqueous solution of $\mathrm{Hg}^{2+}$. Before each measurement and during the titration experiment solution was briefly stirred. The quenching efficiency was calculated using Equation 1,

$$
\text { Quenching efficiency }(\%)=\frac{\left(I-I_{0}\right)}{I_{0}} \times 100
$$

where, $I_{0}$ and $I$ are the fluorescent intensities of before and after addition of $\mathrm{Hg}^{2+}$ aqueous solution to the Mc-CON suspension.

\section{Estimation of Limit of Detection (LOD):}

Limit of detection was calculated by addition an aqueous solution of $\mathrm{Hg}^{2+}$ ion $(1 \mathrm{mM})$ to the $2.0 \mathrm{~mL}$ of stock suspension of Mc-CON in an incremental manner followed by recording the fluorescence emission intensity. Fluorescence intensities were plotted with increasing concentration of $\mathrm{Hg}^{2+}$ ion and LOD was estimated using the Equation 2,

$$
\text { LOD }=\frac{2 S}{\mathrm{~m}} \times 100
$$

where, $S$ is the standard deviation calculated from ten blank measurements of the polymer and $m$ is the slope of the graph derived from the plot of fluorescence intensity vs increasing concentration of $\mathrm{Hg}^{2+}$ ion. ${ }^{\mathrm{S} 3, \mathrm{~S} 4}$ 
Standard deviation Calculation:

\begin{tabular}{|c|c|}
\hline Reading & Intensity (cps) \\
\hline 1 & 134015 \\
\hline 2 & 133125 \\
\hline 3 & 133010 \\
\hline 4 & 132102 \\
\hline 5 & 133230 \\
\hline 6 & 132845 \\
\hline 7 & 132332 \\
\hline 8 & 131875 \\
\hline 9 & 132501 \\
\hline 10 & 133041 \\
\hline Standard Deviation & $\mathbf{6 2 5 . 5}$ \\
\hline
\end{tabular}

$$
3 \mathrm{~S} / \mathrm{m}=0.2241 \mu \mathrm{M}=45 \mathrm{ppb}
$$

\section{Sensing Selectivity Studies:}

To the $3 \mathrm{~mL}$ aqueous suspension of Mc-CON prepared as describe above, $100 \mu \mathrm{L}$ of $1 \mathrm{mM}$ aqueous solution of $\mathrm{HgCl}_{2}$ was added and the change of the fluorescence intensity was monitored. Similar process was followed for the other metal ion solutions maintaining the same condition.

\section{Hg(II) Uptake Kinetics:}

In a glass vial, Mc-CON (50 mg) was added to an aqueous $\mathrm{Hg}\left(\mathrm{NO}_{3}\right)_{2}$ solution of $10 \mathrm{ppm}$ (50 $\mathrm{mL})$ and stirred at room temperature. At certain time intervals, the aliquots $(2 \mathrm{~mL})$ were taken from the mixture and filtered by syringe filter $(0.45 \mu \mathrm{m}$ membrane filter $)$ and the collected filtrates were analysed by ICP-MS to determine the remaining $\mathrm{Hg}^{2+}$ concentration. Removal percentage was calculated by Equation 3,

$$
\operatorname{Removal} \text { efficiency }(\%)=\frac{\left(c_{0}-c_{t}\right)}{c_{0}} \times 100
$$

where, $C_{0}(\mathrm{ppm})$ and $C_{t}(\mathrm{ppm})$ are the initial and the remaining concentration of the $\mathrm{Hg}^{2+}$ in the stock solution and filtrate, respectively at time $t$.

The Pseudo-second-order kinetic is expressed using the Equation 4,

$$
\frac{t}{Q_{t}}=\frac{1}{k_{2} Q_{e}^{2}}+\frac{t}{Q_{e}}
$$

where, $k_{2}\left(\mathrm{~g} \mathrm{mg}^{-1} \mathrm{~min}^{-1}\right)$ is the rate constant of pseudo-second-order adsorption, $Q_{t}\left(\mathrm{mg} \mathrm{g}^{-1}\right)$ and $Q_{c}\left(\mathrm{mg} \mathrm{g}^{-1}\right)$ are the amount of $\mathrm{Hg}^{2+}$ adsorbed at time $t(\mathrm{~min})$ and at equilibrium, respectively. 
Diffusion coefficient, $\mathrm{K}_{\mathrm{d}}$ is determined by the following Equation 5,

$$
K_{d}=\frac{\left(c_{0}-c_{e}\right)}{c_{e}} \times \frac{V}{m}
$$

where, $\mathrm{V}(\mathrm{mL})$, is the volume of the treated solution, $\mathrm{m}(\mathrm{mg})$ is the mass of used sorbent $(\mathrm{g})$, $C_{o}(\mathrm{ppm})$ and $C_{e}(\mathrm{ppm})$ are the initial and the final equilibrium concentration of $\mathrm{Hg}^{2+}$, respectively.

\section{Hg(II) Uptake Isotherm:}

The Mc-CON (10 mg) was added to each $\mathrm{Hg}\left(\mathrm{NO}_{3}\right)_{2}$ solutions $(10 \mathrm{~mL})$ in the separated glass vials at different concentrations at neutral $\mathrm{pH}$. The mixtures were stirred at room temperature for $12 \mathrm{~h}$ and then filtered individually. The filtrates were collected and analysed by using ICP-MS to determine the residual $\mathrm{Hg}^{2+}$ concentration. The adsorbed amount of $\mathrm{Hg}^{2+}$ at equilibrium was calculated by the Equation 6,

$$
Q_{e}=\left(c_{0}-c_{e}\right) \times \frac{V}{m}
$$

where, $V(\mathrm{~mL})$ is the volume of the treated solution, $\mathrm{m}(\mathrm{g})$ is the mass of used adsorbent, $C_{0}$ (ppm) and $C_{e}(\mathrm{ppm})$ are the initial and the final equilibrium concentration of $\mathrm{Hg}^{2+}$, respectively.

The data was fitted with Langmuir adsorption isotherm model as expressed in the following Equation 7

$$
\frac{c_{e}}{Q_{e}}=\frac{c_{e}}{Q_{m}}+\frac{1}{Q_{m} K_{L}}
$$

and Freundlich isotherm model as illustrated in the following Equation 8 as

$$
\ln Q_{e}=\ln K_{F}+\frac{1}{n} \ln C_{e}
$$

where, $K_{L}$ and $K_{F}$ is the Langmuir and Freundlich constant, respectively and $n$ is an empirical parameter related to the intensity of adsorption.

\section{pH Dependent $\mathrm{Hg}(\mathrm{II})$ Uptake:}

The Mc-CON (10.0 mg) was added to $10 \mathrm{~mL}$ aqueous solution of $\mathrm{Hg}\left(\mathrm{NO}_{3}\right)_{2}$ of $10 \mathrm{ppm}$ at different $\mathrm{pH}$ values. The mixtures were stirred at room temperature for 1 hours. Then the suspension were filtered and the filtrates were analysed by using ICP-MS to determine the remaining $\mathrm{Hg}^{2+}$ content.

\section{Adsorption Selectivity Studies:}

The MC-COP $(10.0 \mathrm{mg})$ was added to a glass vial containing a $10 \mathrm{~mL}$ aqueous solution of 
$\mathrm{Hg}\left(\mathrm{NO}_{3}\right)_{2}, \mathrm{~Pb}\left(\mathrm{NO}_{3}\right)_{2}, \mathrm{Cd}\left(\mathrm{NO}_{3}\right)_{2}, \mathrm{Ca}\left(\mathrm{NO}_{3}\right)_{2}, \mathrm{Cu}\left(\mathrm{NO}_{3}\right)_{2}, \mathrm{Cr}\left(\mathrm{NO}_{3}\right)_{3} \mathrm{Zn}\left(\mathrm{NO}_{3}\right)_{2}, \mathrm{Fe}\left(\mathrm{NO}_{3}\right)_{3}$, $\mathrm{Mg}\left(\mathrm{NO}_{3}\right)_{2}, \mathrm{Mn}\left(\mathrm{NO}_{3}\right)_{2}, \mathrm{KNO}_{3}, \mathrm{NaNO}_{3}$ with each concentration of $10 \mathrm{ppm}$. The mixture was stirred at room temperature for $12 \mathrm{~h}$ followed by filtration and the filtrate was analysed by ICP-MS to determine the remaining metals ion concentration.

\section{Recyclability Study:}

The Mc-CON (10 mg) was added to a glass vial containing $\mathrm{Hg}\left(\mathrm{NO}_{3}\right)_{2}$ aqueous solution $(10 \mathrm{~mL})$ of $10 \mathrm{ppm}$ concentration. The mixtures were stirred at room temperature for $12 \mathrm{~h}$, filtered and washed with $50 \mathrm{~mL}$ water. Then the polymer sample was stirred in $10 \mathrm{~mL}$ aqueous ethanedithiol solution (8 equivalents) for an hour. After filtration followed by few times washing with water $(10 \mathrm{~mL})$, the Mc-CON was again used for next cycle. The filtrates were analysed by ICP-MS to determine the $\mathrm{Hg}^{2+}$ concentration.
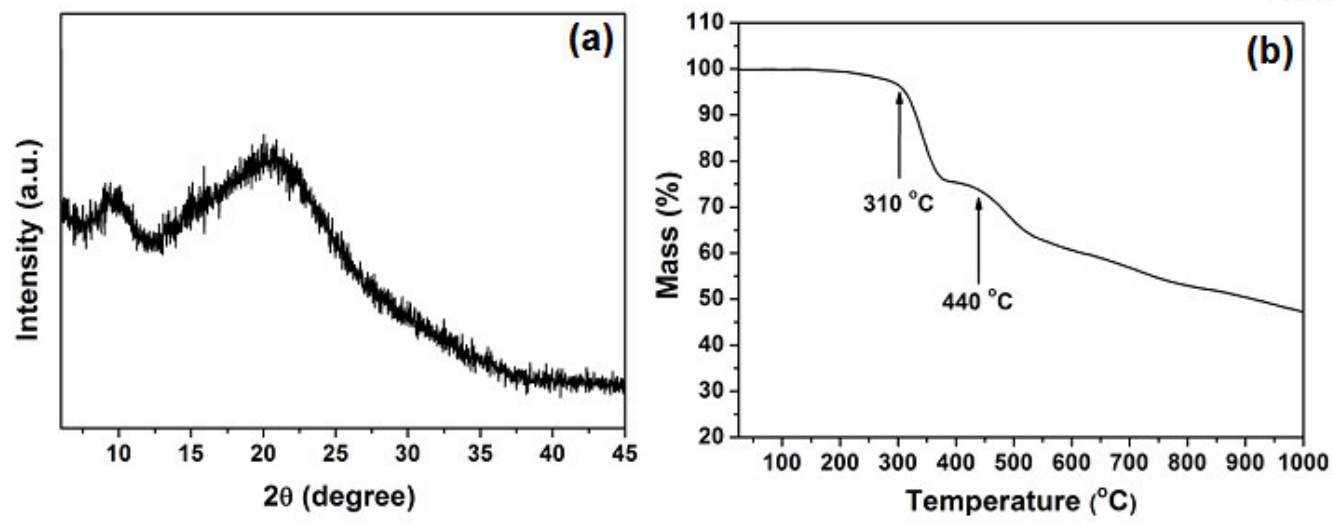

Figure S14. (a) PXRD pattern and (b) TGA analysis of Mc-CON.
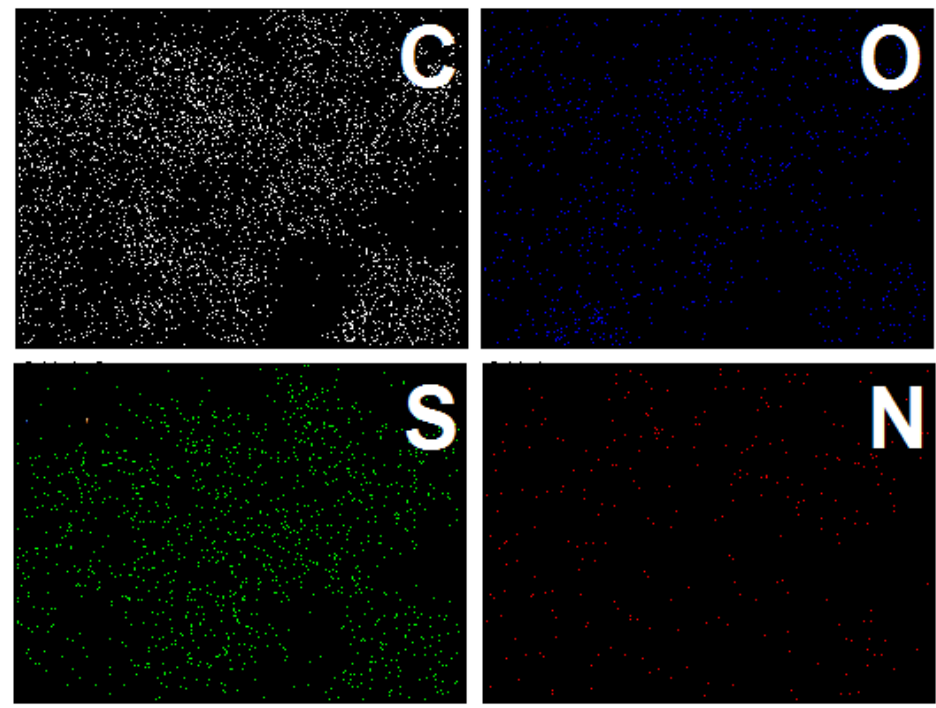

Figure S15. Elemental maping of Mc-CON via FE-SEM. 

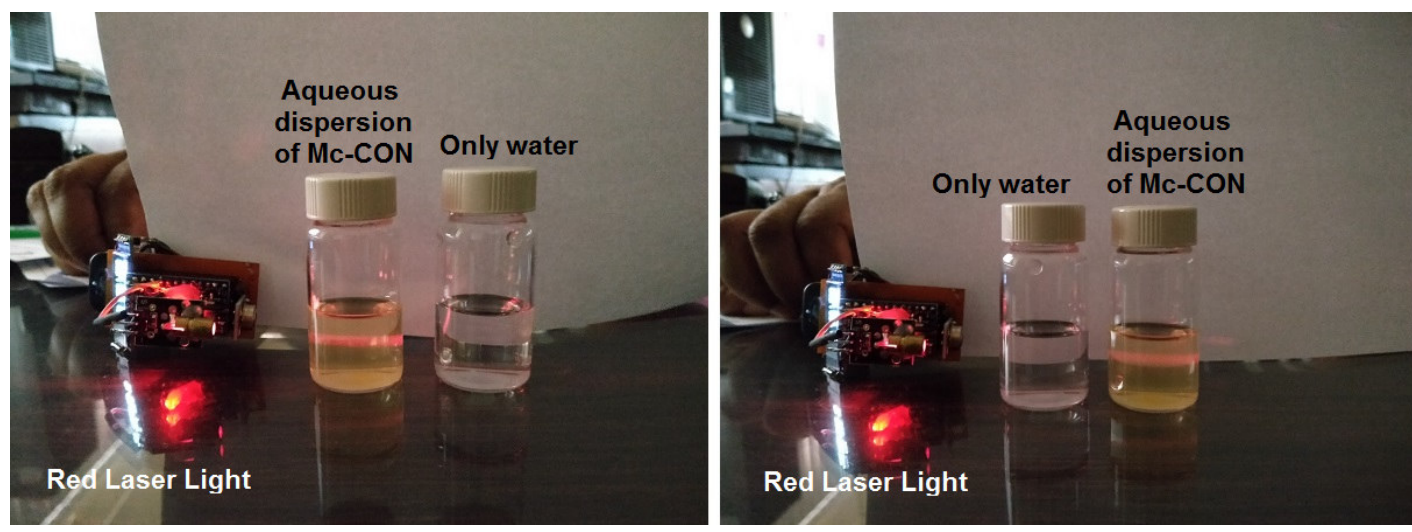

Figure S16. Display of Tyndall effect of aqueous suspension of Mc-CON together with only water.

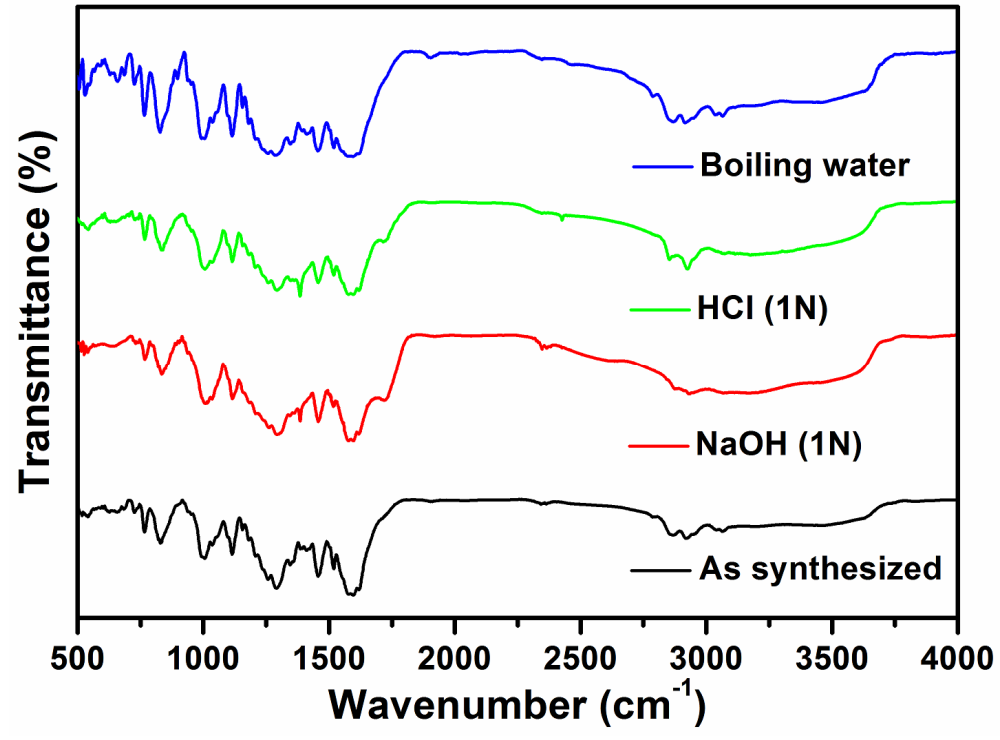

Figure S17. Stability test of Mc-CON under various harsh conditions using FT-IR analysis.

Table S1. Elemental analysis results of Mc-CON via combustion process.

\begin{tabular}{|c|c|c|c|c|}
\hline Method & \% Nitrogen & \% Carbon & \% Hydrogen & \% Sulphur \\
\hline Experimental & 3.83 & 62.58 & 5.01 & 9.61 \\
\hline
\end{tabular}




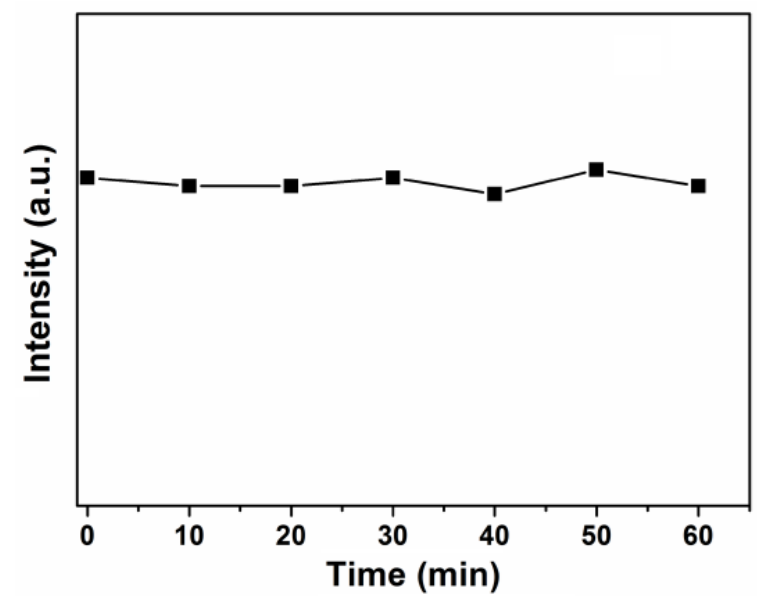

Figure S18. Time-dependent fluorescence intensity measurement of Mc-CON aqueous suspension.
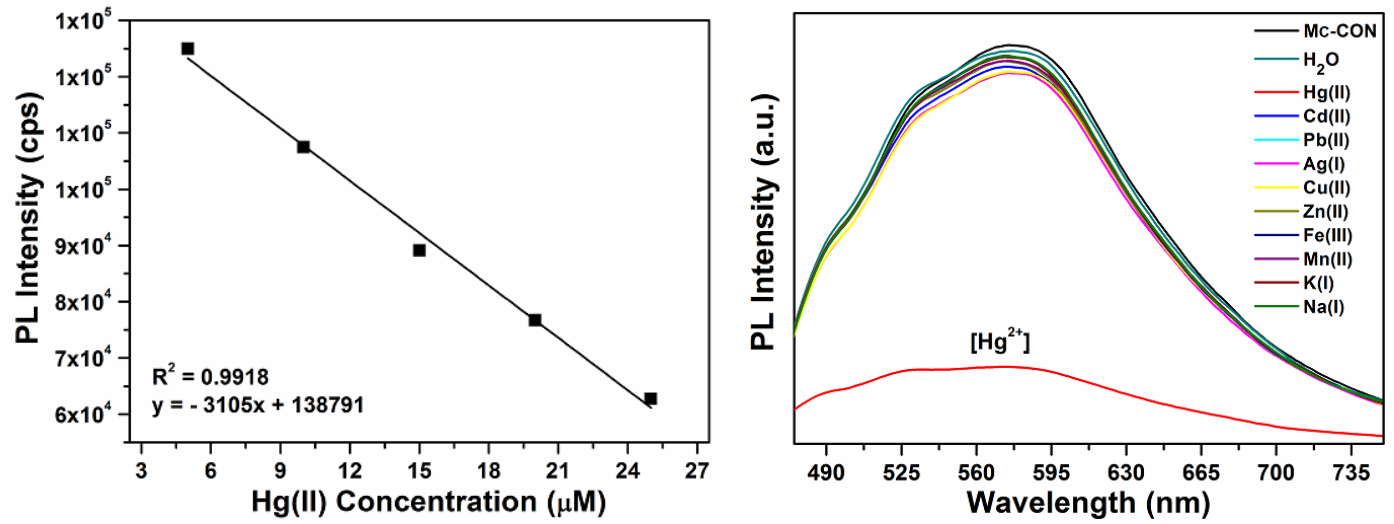

Figure S19. Linear regression of fluorescence quenching with increasing $\mathrm{Hg}^{2+}$ concentration (left) and fluorescence responses of Mc-CON in presence of various metal ions (right)

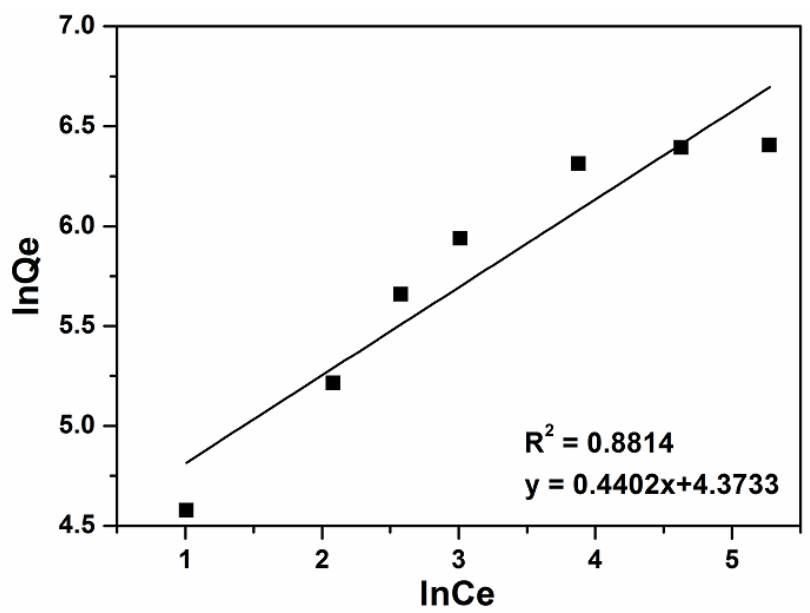

Figure S20: Freundlich adsorption model by fitting the equilibrium adsorption data. 

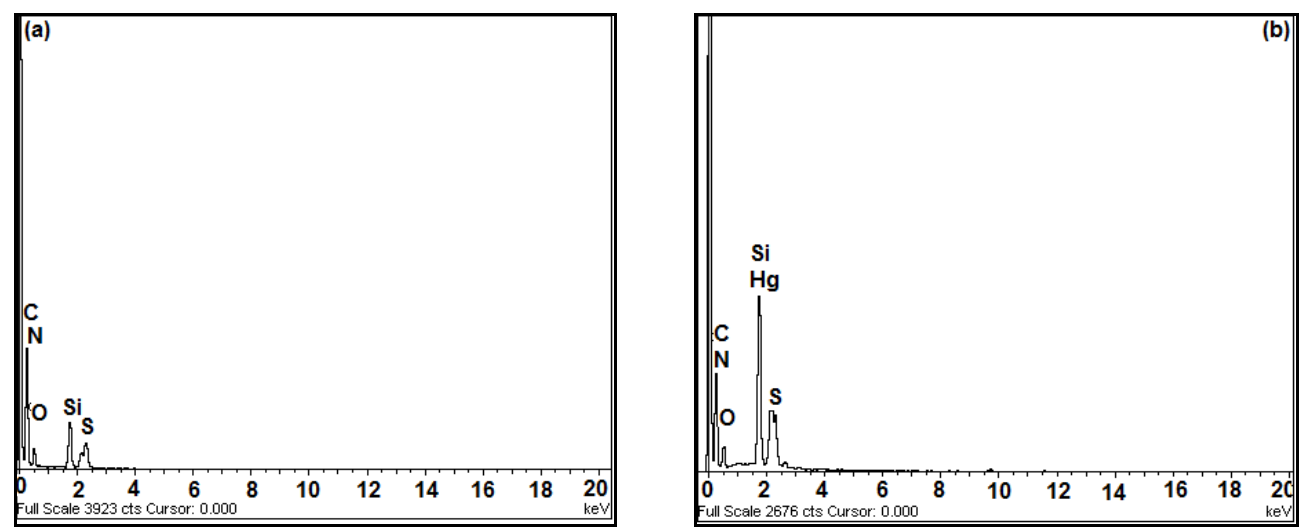

Figure S21. EDX spectra of Mc-CON (a) before and (b) after adsorption of $\mathrm{Hg}^{2+}$.

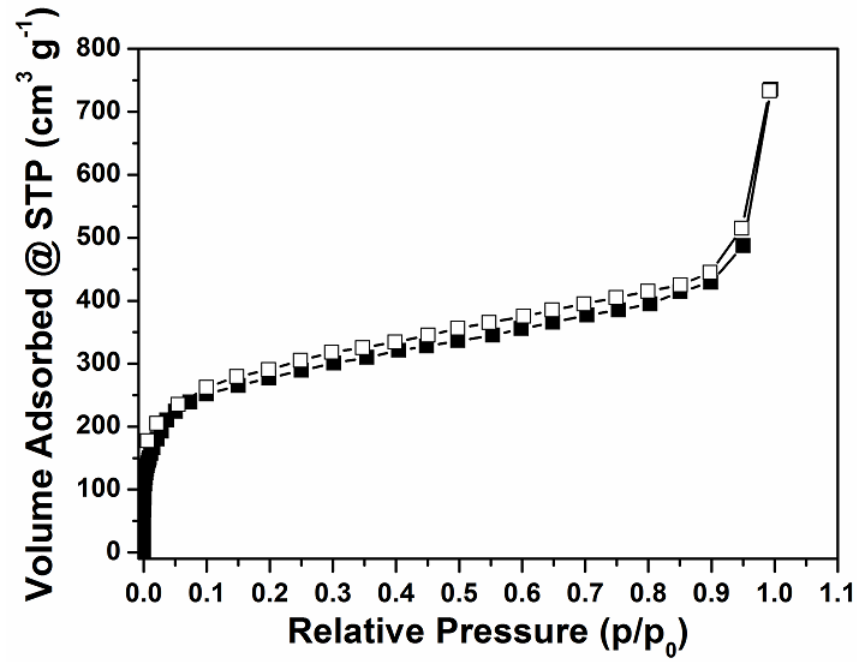

Figure S22. $\mathrm{N}_{2}$ adsorption and desorption isotherms of UCBZ-5 measured at $77 \mathrm{~K}$.

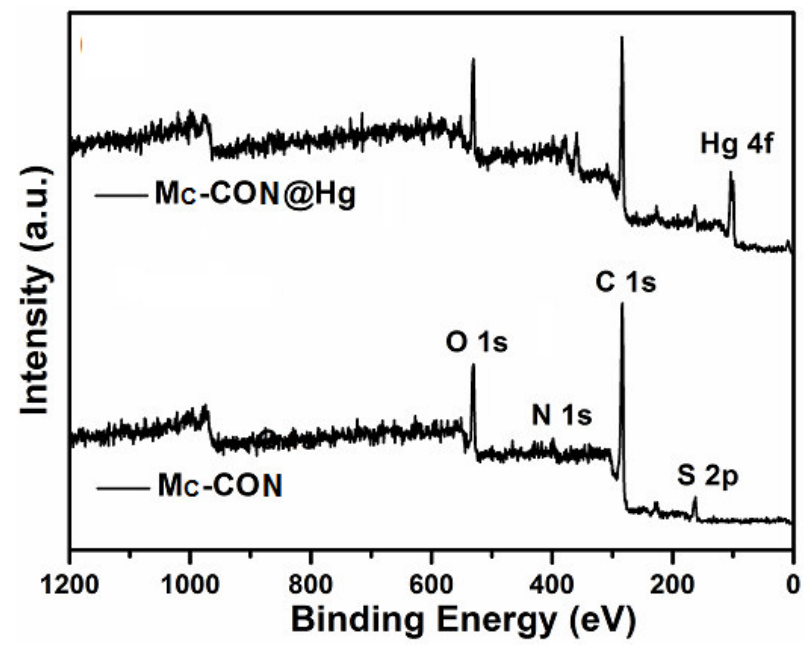

Figure S23: XPS survey spectra of Mc-CON before and after adsorption of $\mathrm{Hg}^{2+}$. 


\section{References:}

S1. Fedorova, O. A.; Vedernikov, A. I.; Yescheulova, O. V.; Pershina, Y. V.; Tsapenko, P. V.; Gromov, S. P. A Facile Method for the Synthesis of Benzothiacrown Ether Formyl Derivatives. Synth. Commun. 2002, 32, 1909-1915.

S2. Zhao, Y. L.; Liu, L.; Zhang, W.; Sue, C. H.; Li, Q.; Miljanić, O. S.; Yaghi, O. M.; Stoddart, J. F. Rigid-Strut-Containing Crown Ethers and [2]Catenanes for Incorporation into Metal-Organic Frameworks. Chem. Eur. J. 2009, 15, 13356-13380.

S3. Long, G. L.; Winefordner, J. D. Limit of Detection. A Closer Look at the IUPAC Definition. Anal. Chem. 1983, 55, 712A-724A;

S4. Hussain, S.; De, S.; Iyer, P. K. Thiazole-Containing Conjugated Polymer as a Visual and Fluorometric Sensor for Iodide and Mercury. ACS Appl. Mater. \& Interfaces 2013, $5,2234-2240$. 